\title{
CONJECTURA SISTÊMICA: OS JOGOS DE PODER NA FEDERAÇÃO RESILIENTE
}

\author{
Marcio Pugliesi ${ }^{\mathrm{i}}$ \\ Nuria López ${ }^{\mathrm{i}}$ \\ Luciano Del Monaco ${ }^{\mathrm{iii}}$
}

Sumário: 1 Introdução. 2 Atmosfera semántica: vontade e decisão. 3 Jogos de poder: faça a sua aposta. 4 A federação em conflito: resiliência. 4.1 PEC-33 e royalties do pré-sal: análise de casos. 5 . Conclusão. Referências.

\begin{abstract}
Resumo
Este artigo parte da perspectiva das relações institucionais como um sistema dinâmico complexo, composto pelas ações de cada um dos sujeitos envolvidos, em que, portanto, os conflitos podem ser compreendidos como jogos de poder (Pugliesi). Muitos dos lances desses jogos consistem em tomadas de decisão institucional acerca do significado pragmático de normas jurídicas, como nos casos brasileiros analisados, da PEC-33 e dos royalties do pré-sal. O impacto dos lances nesse jogo sistêmico de poder é
\end{abstract}

\footnotetext{
i Professor do Programa de Pós-Graduação Stricto Sensu da Faculdade de Direito da Pontifícia Universidade Católica de São Paulo (PUC-SP); Doutor e Livre-Docente em Direito pela Universidade de São Paulo (USP); Doutor em Filosofia pela Pontifícia Universidade Católica de São Paulo (PUC-SP); Doutor em Educação pela Pontifícia Universidade Católica de São Paulo (PUC-SP); email: mpugliesi@hotmail.com.

${ }^{i i}$ Doutoranda e Mestre em Filosofia do Direito pela Pontifícia Universidade Católica de São Paulo, bolsista do CNPQ (PUC-SP); email: nuria.lcs@gmail. com

iii Graduando em Direito pela Faculdade Paulista de Direito da Pontifícia Universidade Católica de São Paulo (PUC-SP); email: lucianomonaco@gmail. com.
} 
analisado a partir da tese de Bednar, ampliada da perspectiva federativa para a institucional, de forma a compreender a dinâmica sistêmica dentro de um design resiliente.

Palavras-chave: Instituições. Teoria dos Jogos. Sistema.

\begin{abstract}
This paper has its start point from the perspective of institutional relations as an complex dynamic system, composed by the actions of each one of the subjects involved, in which, therefore, the conflicts could be understood as power games (Pugliesi). Many of the moves of these games consist in institutional decision making on the pragmatic meaning of legal norms, such as in the Brazilian cases analyzed of PEC-33 and the pré-sal royalties. The impact of these moves in this systemic game of power is analyzed from Bednar's thesis, extended from the federative perspective to an institutional one, in matter to comprehend the systemic dynamics in a resilient design.
\end{abstract}

Keywords: Institutions. Game Theory. System.

\section{INTRODUÇÃO}

$\mathrm{D}$ entre os muitos conflitos institucionais possíveis em uma federação, alguns deles implicam escolha e imposição aos demais de um significado pragmático para determinada norma jurídica capaz de alterar as próprias regras do jogo institucional (constitucional). É o caso do conflito deflagrado entre o STF e o Congresso Nacional, acerca da PEC-33 ou ainda dos conflitos entre os entes federativos, como a celeuma envolvendo a divisão dos royalties do pré-sal.

Este trabalho propõe a utilização de um novo marco teórico para compreender os conflitos institucionais e precisar em que momentos a alteração da interpretação das normas jurídicas quanto ao design institucional podem ser desejáveis ou indicar a destruição da federação como a conhecemos. Evidentemente, não se trata de antever ou prever quaisquer mudanças no quadro institucional, bem como defender este ou aquele modelo - na verdade se trata mais de compreender como a federação em si opera.

Em síntese, ao invés de utilizarmos um marco teórico mais usual, que é o já clássico modelo de divisão dos poderes e competências, no qual a Constituição (e a legislação infraconstitucional) estabelecem previamente o design institucional, e a interpretação da norma jurídica é orientada para a manutenção desse modelo - optamos por buscar uma fundação na realidade fática e não em comandos de dever-ser.

Assim sendo, não há de se falar, por esse prisma teórico, sobre interpretações jurídicas "equivocadas" e "corretas", mas sim as que são aceitas (ou ao menos toleráveis) e as não aceitas dentro de um design institucional pelos agentes que possuem capacidade de barganha. Não consideramos a atividade do Judiciário como a "interpretação da lei para fins de cumprir a constituição", mas sim a "interpretação da lei para fins de cumprir a agenda da instituição e de seus membros"'.

Dentro dessa abordagem de cunho nitidamente sociológico o objetivo do presente trabalho é compreender dois fenômenos 
distintos, a conjectura sistêmica institucional (que abrange desde a formação da vontade da institucional, a sua agenda e seus meios de ação), e os jogos de poder institucionais (como o conflito se desenrola). Para analisar o primeiro ponto utilizaremos o conceito de atmosfera semântica de Pugliesi e o conceito de federação resiliente de Bednar.

\section{ATMOSFERA SEMÂNTICA: VONTADE E DECISÃO}

Cumpre primeiro esclarecer que o próprio conceito de atmosfera semântica deriva de uma teoria maior, que é a conjectura sistêmica, que pode ser muito bem compreendida pontuandose que suas origens remontam à Teoria Geral dos Sistemas(elaboradainicialmenteporBertalanffy ${ }^{2}$ ) e a Teoria dos Jogos e da Estratégia (oriunda da obra de Von Neumann e Morgenstern); e, filosoficamente, constitui superação dialética entre consciência e linguagem.

Compreende-se de plano que se trata de uma abordagem teórica que se imerge no conceito de complexidade; logo, é bem evidente que para nós as instituições (Judiciário, estados, autarquias etc.) são tudo menos divisões estanques do poder Estatal em vista de realizar melhor a função previamente definida na legislação, são, antes de mais nada, sujeitos.

Pode-se compreender, combase na "conjectura sistêmica" desenvolvida (Pugliesi, 2013, parte 2 - "Conjectura", capítulo 3) cada instituição como uma rede de atmosferas semânticas que é constituída pela atmosfera semântica de cada indivíduo que a compõe, e que ocupam posições distintas nela, ao mesmo tempo em que existe uma atmosfera semântica institucional, da própria instituição. A existência desses dois conjuntos de atmosferas (as individuais e a institucional) deriva da existência de falhas de comunicação e sinergia dentro da instituição. Um indivíduo não é capaz de plasmar sua atmosfera para a instituição, nem a instituição é capaz de se sobrepor à atmosfera do indivíduo - e essa é uma constatação da própria realidade fática, motivada pela existência do fenômeno que se chama de "ruído"3 em qualquer processo de comunicação. Em linhas gerais, pode-se afirmar que o "ruído" é o que impede a comunicação totalmente eficiente (na qual os interlocutores compreendem perfeitamente a mensagem transmitida, sem perdas); logo; sempre existirá um mínimo de divergência entre os interlocutores.

De forma quea tomada de decisão institucional pela construção de determinado significado pragmático para a norma jurídica é uma tomada de decisão dos indivíduos com competência institucional para tanto uma tomada de decisão da instituição em si e calcada por uma agenda, que também engloba interesses particulares e institucionais, haja vista que a composição do sujeito enquanto atmosfera semântica não comporta tais cortes epistemológicos.

Até o momento é possível a existência de certa confusão no que refere à possibilidade de uma atuação conjunta de duas atmosferas (as individuais e as institucionais), sob o mesmo objeto e ao mesmo tempo.

É nesse ponto que se faz útil aprofundar o conceito de atmosfera semântica, que por ser um conceito complexo (que depende de outros conceitos), pode ser definido como:

$\mathrm{O}$ conflito é uma condição inerente ao ser humano e as diferenças decorrentes dos distintos estados de conhecimentodossujeitosem comunicação mantêmum permanente estado conflitivo. Entende-se por estado de conhecimento: uma cosmovisão em um determinado instante da sucessão temporal constitutiva dos estados de um dado sujeito, isto é, um corte no quase-contínuo chamado sujeito que, sob o ponto de vista da posição gnoseológica orientadora deste trabalho, poderá ser representado por um conjunto de informações; dados

\footnotetext{
${ }^{1}$ Em síntese, colocamo-nos contrários a qualquer interpretação teleológica ou finalística da federação e das normas constitucionais (e infraconstitucionais). Diferentemente do exposto, por exemplo, por John Rawls, em "Uma teoria da Justiça", não pressupomos a prefixação de conceitos aptos a explicar e dar sentido a interpretações jurídicas, como também não admitimos a existência de uma finalidade última a ser alcançada, como a "justiça", no caso de Rawls.

${ }^{2}$ Ver, a respeito, “Teoria Geral dos Sistemas”, de Ludwig Von Bertalanffay, especialmente os capítulos 1 e 3.

${ }^{3}$ Para uma melhor definição de ruído, ver a obra de Ashby Ross, intitulada "An Introduction to Cybernetics", p.186-187. Oportuno reafirmar que o "ruído" não é inerentemente diferente da comunicação que se pretende realizar; trata-se de uma "valoração" do comunicante (e do ouvinte) que valora, com base em seus valores (sua atmosfera semântica), como agir diante dessa comunicação.
} 
desestruturados; ideologias; pulsões inconscientes, teorias assumidas e pressupostas; expectativas e temores; desejos formulados etc. ou, para se empregar uma metáfora: uma atmosfera semântica com sua respectiva poluição, também semântica. À medida que o tempo flui, o estado de conhecimento se modifica e, em consequência, o sujeito. Não se esquecendo que, por vezes, até por questões metodológicas, o sujeito pode constituir-se, para si mesmo, em alteridade [grifos nossos].

Diversos aspectos devem ser destacados do trecho citado, comecemos com o principal: a atmosfera semântica é um conjunto de informações, informações essas que derivam do conhecimento do mundo do sujeito (visão que o sujeito possui sobre o mundo em determinado instante) - assim sendo, o sujeito é a atmosfera semântica, pois esta o representa como uma totalidade. Acreditamos que essa conceituação se coaduna precisamente com o quadro de complexidade estrutural da sociedade contemporânea. Caso estivéssemos tratando de uma instituição, poderíamos elencar, dentro desse conjunto de informações, outros dados, tais como a história da instituição, sua tradição, tendência (de formação e de classe social, por exemplo) de seus membros, influência política, e outros.

Ainda não resolvemos a questão da atuação conjunta de duas atmosferas semânticas, e para solucionarmosessadúvidaéquesalientamosquea atmosfera é semântica, assim como sua respectiva poluição. Expliquemos. Primeiramente, utilizase o vocábulo "atmosfera" precisamente para demonstrar que não são núcleos inteiriços, ou seja, não existem choques de atmosferas semânticas, mas sim uma interação mútua, superposição, entre duas (ou mais) atmosferas semânticas - a "intersecção" é exatamente isso parcela de uma atmosfera ${ }^{5}$ que está em contato (dentro) de outra atmosfera, vista pela ótica de outra atmosfera.
A distinção entre atmosfera semântica e poluição advém de uma distinção conceitual. A poluição é o "meio" (no qual o sujeito se insere), isso quando temos como referência a atmosfera como "sistema". O sujeito vê a si mesmo (sua própria atmosfera semântica) como atmosfera, e todo o influxo exterior (de outras atmosferas semânticas, enquanto parte do meio), como poluição que está "contaminando-o"'. Poluição essa que tende a alterar a composição de sua própria atmosfera, e, de certa forma, alterar o próprio sujeito:

O sujeito age, a partir das regras do jogo e de seu conhecimento das circunstâncias, corrige sua ação e busca conferir os efeitos da atuação sobre o sistema (subconjunto do mundo, entendido como sua atmosfera semântica e a respectiva poluição) e o meio, a totalidade das aspecções possíveis a ele, e então, por assim dizer, retroage, isto é, realimenta seu próprio cabedal de informações e refaz, quando possível, a decisão preliminarmente assumida, recompondo sua teoria [grifos nossos].?

Restando claros esses conceitos, segue-se a seguinte conclusão: o conflito é uma condição inerente ao ser humano, não no sentido de "conflito" apenas como um conceito meramente opositivo (existência de uma situação e de uma oposição). O conflito é inerente ao convívio do sujeito em sociedade; a vida em sociedade é uma constante interação entre atmosferas semânticas que se "interseccionam" (poluemse) mutuamente e se alteram, tornando-se assim "novas" atmosferas semânticas, novos sujeitos ${ }^{8}$.

Dessa forma, é evidente a possibilidade de existência, dentrodeumainstituição, daatmosfera de cada indivíduo e da atmosfera institucional, e do seu convívio mútuo - pois uma atua sobre a outra e vice-versa, em um constante fluxo de troca de informações. Interessante também salientar que, dependendo de como observado o sujeito, é possível que ele seja, para si mesmo,

\footnotetext{
${ }^{4}$ PUGLIESI, Marcio. Filosofia geral e do direito. 2013. p. 157-159.

${ }^{5}$ Não é possível fragmentar ou compartimentar uma atmosfera semântica, o que procuramos explicar ao falar de uma parcela de atmosfera é que nem sempre, e na maioria das vezes isso não acontece, uma atmosfera semântica se conecta (se sobrepõe) a apenas parcela de outra atmosfera, existindo apenas uma pequena área de intersecção (aconselhamos observar essa interação como uma teoria de conjuntos, como um diagrama de Veen, por exemplo). ${ }^{6}$ Pontue-se que esse é o ponto de vista do sujeito. Ao observarmos o quadro por um viés mais amplo o que vemos é a ocorrência de uma intersecção entre atmosferas semânticas diferentes (indivíduos) e uma poluição (do meio) atuando sobre os sujeitos.

${ }^{7}$ PUGLIESI, Marcio. Filosofia geral e do direito, p. 185-186.

${ }^{8}$ Trata-se de um "novo" sujeito porque este alterou seu conjunto de informações, sua atmosfera semântica, obviamente não se está a afirmar que esse "novo" sujeito é completamente distinto do anterior, mas possui elementos que o tornam diferente e, por isso, "novo".
} 
uma alteridade ${ }^{9}$ - uma disputa interna em uma instituição pode chegar até mesmo a romper a unidade da atmosfera institucional, podendo chegar a formar grupos bastante distintos.

Sob o prisma teórico utilizado, a tomada de decisão e a formação de uma agenda perpassam uma cadeia complexa de pontos, que vão desde pontos macroestratégicos (falta de recursos, por exemplo), até idiossincrasias dos indivíduos que detêm a competência para decidir pela instituição.

\section{JOGOS DE PODER: FAÇA A SUA APOSTA}

O conceito de atmosfera semântica nos fornece um instrumental teórico que permite realizar um procedimento bastante singular, igualar (como estruturas teóricas) instituições e indivíduos, que são passíveis de abordagem como "sujeitos". Portanto, é teoricamente ${ }^{10}$ possível identificar como se dá a influência da atmosfera de um sujeito sobre outro.

Avancemos um passo e nos voltemos a um conflitoinstitucional,noqualépossívelvislumbrar de maneira mais clara as atmosferas semânticas (institucionais) em conflito ${ }^{11}$. O conflito entre as tomadas de decisões das instituições, disputando melhores posições no design institucional, pode ter sua análise pautada pela teoria dos jogos intersecção entre Pugliesi e Bednar, para quem os jogos institucionais implicam desvios de poder que lhe são inerentes e até desejáveis para alterações da estrutura federativa. A federação é resiliente. Seu design suporta que os lances desses jogadores institucionais alterem sua própria posição, o que até certo ponto pode ser considerado uma evolução sistêmica ${ }^{12}$. Para tanto são necessárias salvaguardas (safeguards) institucionais - judiciárias e políticas; a possibilidade de retaliação intergovernamental; e algumas características estruturais básicas.

A resiliência da federação é uma característica bastante importante que não é tratada nas análises usuais sobre a federação, o "pacto federativo" não é um acordo formalizado em tábuas de lei; é um design que deriva das tensões políticas e sociais em conflito - logo não se deve esperar a perenidade de um modelo. Ao mesmo tempo em que se espera um mínimo de estabilidade social, motivo pelo qual existem as salvaguardas institucionais, que objetivam bloquear certas mudanças e permitir outras ${ }^{13}$.

A forma pela qual a estrutura se altera, que são os desvios de poder, resulta da própria intersecção mútua entre atmosferas semânticas diferentes, no caso em questão, sobre instituições diferentes ${ }^{14}$.

Antes de adentrarmos a Teoria dos Jogos propriamente dita é necessário estabelecer algumas premissas (cortes epistemológicos) que norteiam nossa análise. Primeiramente, todos os conflitos institucionais estão inseridos dentro do escopo do Direito; logo, o conflito é limitado ao racional com respeito a fins, limita-se o aspecto irracional da conduta ao valor utilidade do objetivo, o qual será variável para cada sujeito ${ }^{15}$.

Restando delimitadas as premissas, tratemos da Teoria dos Jogos. No campo dos conflitos institucionais, o fato de dois sujeitos opostos possuírem o mesmo objetivo não impede que seja possível uma cooperação; assim sendo, os

\footnotetext{
${ }^{9} \mathrm{O}$ indivíduo passa a ser, dessa forma, "eu" e "outro". É "eu" na medida em que visto de sua atmosfera individual, mas é "outro" enquanto membro de uma instituição, subordinado a suas regras. De certa forma é possível expandir essa conclusão, porém, em síntese, deve-se reforçar a existência desse descompasso entre o sujeito enquanto "eu" e enquanto "outro".

${ }^{10}$ Toda ênfase deve ser dada ao "teoricamente" da sentença, pois embora os influxos estejam no mesmo patamar, informações que afetam o estado de conhecimento do sujeito, não é possível determinar de maneira objetiva como uma atmosfera polui outra e qual a intensidade dessa poluição, bem como efeitos a serem esperados (sabe-se que existe a possibilidade de mudança, mas como el ocorrerá e em qual nível, isso não é possível antever).

${ }^{11}$ Essa maior facilidade deriva apenas do fato de que a instituição é um sujeito maior, que causa mais impacto no meio social por propagar de forma mais efetiva sua atmosfera, que é mais reconhecível no meio social do que a de um indivíduo considerado de forma pontual; além disso, é mais fácil reconhecer a agenda de uma instituição pois sua formulação é um processo contínuo, decorrente de conflitos com outras instituições.

${ }^{12}$ BEDNAR, Jenna. The robust federation - principles of design. Cambridge: Cambridge University Press, 2009.

${ }^{13} \mathrm{Um}$ exemplo interessante de salvaguarda institucional que bloqueia e ao mesmo tempo permite mudanças é o próprio Judiciário, que por possuir competência para declarar a inconstitucionalidade de uma lei é capaz de bloquear mudanças no design federativo e, por meio dessa mesma competência é capaz de permitir mudanças na estrutura federativa, ao influenciar uma determinada política pública, por exemplo.

${ }^{14}$ Relevante acrescentar que qualquer decisão representa um acréscimo cognitivo de quem decide (e sobre quem a decisão acarreta efeitos), levando-se assim a um processo de interação permanente e de constante reconfiguração de limites e metas a serem atingidos.

${ }^{15}$ É possível falsear essas premissas, contudo tal delimitação é assaz útil para realizar uma precisa explicação da teoria por nós utilizada.
} 
“jogos institucionais" não são os chamados jogos de soma zero (no qual é impossível a negociação por se estar em um quadro de escassez, a vitória de uma das partes implica, impreterivelmente, a derrota da outra). Embora seja possível que na prática se observem alguns jogos de soma zero, não se trata essa de uma regra (no escopo de que tratamos poderia até se dizer que jogos de soma zero se configuram como verdadeiras exceções).

Diante desse quadro, os conflitos se resumem a estratégias de negociação, as quais podem assumir distintas formas. Como regra geral é possível afirmar que as negociações orbitam entre dois polos - o da intimidação e o da barganha - com o intuito último de "fixar as posições não desejadas como sendo as mais favoráveis a obter para a parte contrária, em outras palavras, transformar aquilo que se deseja em a mais vantajosa concessão a ser feita pela parte contrária, de tal modo que, se possível, esta o faça de boa mente" 16 .

Não ignoremos a existência de fenômenos que aumentam a complexidade do processo conflitivo, a saber: a simulação e o logro. É um quadro bastante complexo, especialmente se observado no mundo fático, pois a cada ação/omissão de uma das partes em conflito existe a possibilidade de se tratar de um logro/simulação.

Ao considerarmos a existência desse quadro complexo, um jogo no qual as regras se misturam com os objetivos, é evidente que a decisão em si é mais parte da estratégia negocial do que uma decorrência lógica.

Expliquemos: poder-se-ia dizer que a decisão ("vitória" ou "derrota") é uma decorrência lógica quando delimitada por valores objetivos, por exemplo, o candidato que obter o maior número de votos na eleição é eleito (vence). Agora, esse não é o caso no qual não exista uma decisão correta ou última a ser realizada, por exemplo, realizar ou não um acordo de leniência? Não há, a priori, nada que obrigue o sujeito a realizar tal ato, mas ao fazê-lo (tomar uma decisão que lhe será vantajosa e desvantajosa ao mesmo tempo, tendo ele ponderado esses valores) estará sujeitando-se às consequências da prática, ou da não prática, do ato.

As palavras de Pugliesi sintetizam a explicação exposta até o momento: (Pugliesi, 2013, p. 195):

Mais claramente: sob o ponto de vista de um enfoque negocial do Direito, uma decisão não é verdadeira ou falsa (como, aliás, de modo algum o será), nem correta ou incorreta; uma decisão será conveniente ou inconveniente, pressupondo um quadro situacional (estado de coisas) e os estados de conhecimento, no sentido adotado nesta conjectura, de todos os envolvidos a qualquer título.

Assim, o efetivo poder negocial consistiria em estabelecer, para os eventuais contendores, condições de contorno aptas a fazê-los aceitar a situação mais desejável para quem lhas oferece [grifos nossos] ${ }^{17}$.

\section{A FEDERAÇÃO EM CONFLITO: RESILIÊNCIA}

No tópico anterior procuramos expor como as bases de um conflito, as "regras gerais"18 de como um conflito (jogo) institucional se desenrola em nível estratégico, ou seja, quais os quadros possíveis de ação em um determinado jogo, bem como algumas premissas (como a racionalidade voltada a fins). No entanto, não se abordou especificamente como esse conflito ocorre na realidade, de quais maneiras é possível ocorrer um conflito institucional na federação, bem como identificar esses conflitos ${ }^{19}$.

Um esclarecimento deve ser realizado: o marco teórico desenvolvido por Bednar se volta para o estudo da federação, a dinâmica entre União e estados-membros (considerando

\footnotetext{
${ }^{16}$ PUGLIESE, Marcio. Filosofia geral e do direito, p. 194

${ }^{17}$ PUGLIESE, Marcio. Filosofia geral e do direito, p. 195.

${ }^{18}$ É plenamente possível que esse conjunto seja mais vasto do que ao aqui exposto, o qual trazemos para cumprir os fins deste trabalho, que é a análise de conflitos institucionais dentro da federação resiliente.

${ }^{19}$ Como já frisamos, o Direito estabelece o regramento federativo e os conflitos ocorrem dentro dessas regras; não são conflitos totais que ignoram completamente as regras estabelecidas (não são casos de conflito armado, por exemplo), mas casos nos quais o conflito se dá nos limites das regras, cada sujeito procura interpretá-las/aplicá-las da maneira mais conveniente aos seus interesses (agenda).
} 
que essa teoria se constrói sobre a experiência estadunidense de federalismo). Ao utilizarmos essa teoria extrapolamos seu campo inicial de construção, expandindo-a para toda e quaisquer instituições (a princípio apenas as relacionadas ao Estado) - por estarem sujeitas aos mesmos fatores que esses sujeitos: (i) possuem atmosferas semânticas; (ii) são jogos de conflitos sujeitos às regras do Direito e (iii) estão inseridos no contexto da federação.

A ideia central do trabalho de Bednar é precisamente o fato de que a federação é resiliente. Importante dizer que resiliência é um conceito emprestado da ciência dos materiais - é uma característica de determinados materiais que se alteram sem se romper. É, portanto, uma ideia análoga, dizendo que a federação suporta diferentes desenhos, alterados a todo instante, em razão dos jogos de poder institucional.

Dentre os diversos marcos teóricos possíveis sobre a federação, optamos pelo da "federação resiliente",precisamenteporqueessemarcoteórico permite a análise dos casos concretos específicos de conflitos na federação como jogos de poder, a fim de apontá-los como movimentos sistêmicos que alteram o design federativo e podem implicar adaptação a necessidades prementes, resiliente a falhas e choques externos, e capacidade de dissuadir transgressões oportunistas como a evasão [shirking] de responsabilidades para outra instituição; transferência de ônus [shifting (the burden)]; ou sobrecarga [encroaching (the burden away)] de ônus para instituição diversa.

Uma característica bastante interessante desse modelo é que as transgressões oportunistas ${ }^{20}$ não são elementos desconexos; existe uma intrínseca relação entre cada tipo de transgressão, relacionado a qual ente instituição é mais apto a praticá-lo. Para demonstrar melhor esse quadro apresentamos a figura abaixo ${ }^{21}$ :

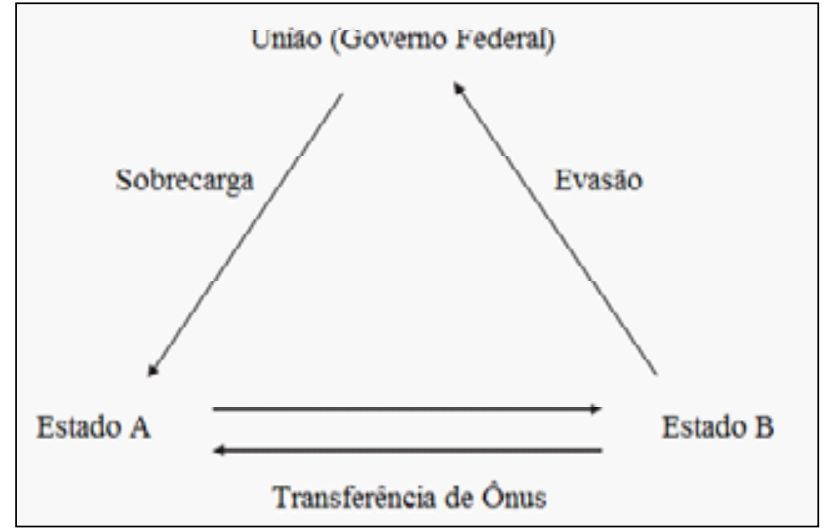

Como é possível observar, pela própria nomenclatura (sobrecarga; evasão; transferência de ônus) é acentuado o caráter negativo dessas atitudes, tratadas comumente como transgressões a serem combatidas - "patologias" do sistema federativo ${ }^{22}$. Não é esse o nosso enfoque, muito pelo contrário, as transgressões podem ser benéficas eimplicar uma "evolução sistêmica", mas também podem ser completamente desastrosas para a federação (e consequentemente para todo o sistema institucional do Estado). A questão se dá na gradação da transgressão, o quão tolerável ela é:

Opportunism [transgressões] may be blatant or ambiguous. In any society there are examples of opportunism that clearly lie out of bounds, but a significant range of actions exists that are less clear-cut: some within the society would call it opportunism, while others would not. As long as the federation is functioning well, probably the majority of opportunism that does occur lies within this range of ambiguity [grifos nossos]. ${ }^{23}$

As transgressões podem, se toleráveis (pelas outras instituições), operar como um modificador do estado de equilíbrio do sistema, promovendo um rearranjo de poder entre as instituições.

Esse é o quadro-base da estratégia negocial desses jogos de poder, no qual a transgressão é uma ação voltada a fins, e o conflito é regulado

\footnotetext{
${ }^{20}$ Essas transgressões não se equiparam necessariamente à corrupção, é possível que em um ambiente permeado de transgressões institucionais, ao pacto federativo, por exemplo, possua pouco ou nenhuma influência do fenômeno "corrupção", como em caso de disputas ideológicas entre estados - como ocorreu durante a Guerra dos Farrapos.

${ }^{21}$ Trata-se da mesma tabela que consta na página 68 da obra de Jenna Bednar, apenas traduzimos os termos (The robust federation - principles of design).

${ }^{22}$ Pontuando mais uma vez que por federativo também abarcamos o sistema institucional (estatal).

${ }^{23}$ BEDNAR, Jenna. The robust federation - principles of design, p. 69.
} 


\section{PESQUISAS SOCIOJURÍDICAS}

(ou melhor dizendo, mantido sob controle) por salvaguardas [safeguards] institucionais que evitam que o conflito saia de controle - existe uma transgressão que pode levar a um conflito descontrolado (retaliação intergovernamental), que deve ser evitado ao máximo mediante o emprego de salvaguardas institucionais.

O conceito de retaliação intergovernamental [institucional] ${ }^{24}$ é bastante relevante para a compreensão desse tipo de jogo. Pelo prisma do Direito, a retaliação intergovernamental é um quadro a ser evitado, e para tanto são construídas regras jurídicas que regulam a situação, de forma que, para o Direito, seria “impossível” existir o conflito - pois se as regras forem obedecidas o sistema permanecerá estável.

No entanto, as regras jurídicas são construídas para as situações "normais", mas caso ocorra uma situação "excepcional", que desestabilize o sistema, estará ela fora do Direito, que não previa esse quadro, e logo também não será possível a negociação.

A impossibilidade da negociação é uma consequência direta da inexistência de regras a regular o jogo, sem a existência de regras não há balizas aptas a delimitar as expectativas de cada parte e, consequentemente, não é possível "transigir".

A experiência histórica mostra casos nos quais a retaliação institucional ocorreu justamente quando a situação fática (transgressão) não era prevista pelo Direito e inexistia possibilidade de negociação.

Um caso que vale a pena ser citado é o da ascensão de Adolf Hitler à chancelaria alemã e, posteriormente, a sua dominação absoluta do poder político alemão. Hitler foi nomeado chanceler por Hindenburg (Presidente), de forma legítima e dentro do ordenamento jurídico alemão; o motivo da escolha foi político Hindenburg pretendia obter o apoio da principal bancada no parlamento - mas a nomeação foi legal.

Com a morte de Hindenburg, a situação era, do ponto de vista jurídico, bastante simples: deveriam ser convocadas novas eleições e o chanceler (Hitler) governaria. Nesse ínterim, o que ocorreu foi, no entanto, uma quebra de expectativa: Hitler decidiu apossar-se do poder e, ao fazê-lo, agiu de forma claramente ilegal. É nesse aspecto que as regras jurídicas só preveem situações "normais": a morte de um presidente é algo ao menos factível, mas a possibilidade de que o chanceler realize um golpe de estado é algo "excepcional".

O que nos interessa desse exemplo é que, dentro desse design institucional existia uma regra clara a ser seguida em caso da morte do presidente e, ao se romper com essa ordem, não existe mais solução juridicamente possível, não ocorreu uma mera "evasão" ou "transferência de ônus", e sim uma transgressão muito mais profunda (um golpe de estado). A República de Weimar era uma federação, a qual possuia resiliência, contudo havia sempre um limite para essa resiliência, o golpe de estado foi superior a essa resistência e terminou por destruir a República de Weimar.

O golpe de estado nazista foi um evento "excepcional" e que não só não foi evitado por nenhum tipo de salvaguarda como também estava além de qualquer possibilidade de negociação. Tratou-se de um caso extremo: a transgressão (o golpe de estado) era intolerável ao governo e não existiam meios jurídicos/ políticos de solução do conflito. Esse é um claro caso de jogo de soma zero, existiam dois grupos (nazistas e seus opositores) em conflito sobre a dominação do poder estatal alemão e apenas um deles poderia obtê-la.

A única solução possível nessa hipótese foi a retaliação institucional, ambos os grupos utilizaram a força armada (e estratégica) que detinham e o grupo que possuía maior força se impôs - situação bastante distinta do que ocorreria dentro de um quadro institucional estável, no qual o poder seria disputado em eleições organizadas por regras pré-estabelecidas e conhecidas pelos participantes.

Em síntese, para o bom funcionamento

${ }^{24}$ Novamente, o conceito é pensado para funcionar sob um esquema federativo, entre governos distintos; trazemos aqui o conceito em uma maior amplitude. 
institucional, a retaliação deve ser mantida ao mínimo possível, contida por salvaguardas, para que se mantenha um quadro regido pelo Direito (que estabelece as regras do jogo) e no qual é possível negociação estratégica. Caso haja algo similar ao ocorrido no exemplo descrito, no qual simplesmente não existem regras do jogo, a única solução possível é retaliação mútua, que pode vir a desencadear um conflito armado - que é exatamente o que não se quer dentro de um Estado.

Restando clara a grande importância das salvaguardas dentro de um design institucional, que atuam como reguladores de conflitos submetendo-os a balizas que abarcam tanto os procedimentos (processo eleitoral, o processo judicial etc...) como os objetivos que podem ser perseguidos por meio desse procedimento (é impossível, no processo eleitoral brasileiro, ser eleito sem ser filiado a partido político, é um objetivo que não pode ser perseguido por esse procedimento).

Em última análise, as salvaguardas são "gatilhos" que reagem à determinada situação fática, mediante uma resposta previamente definida;oqueos diferenciaéque cada salvaguarda reage a um estímulo específico e provê um tipo de resposta. A título exemplificativo, trazemos o rol de salvaguardas de Bednar para ilustrar essas diversas formas: "In addition to the primitive, fundamental safeguard of intergovernmental retaliation introduced in this chapter; further safeguards may be structural, popular, political, or judicial." 25

A retaliação institucional (intergovernamental) também é uma salvaguarda, mas é uma salvaguarda última, no sentido de que desencadeia as respostas mais agressivas a uma transgressão (como no exemplo histórico citado), mais interessantes e úteis ao quadro institucional são as demais salvaguardas. É possível definir essas outras salvaguardas como:

1. Structural, including fragmentation of the national government and giving the state a voice in national decision making;

2. Popular, when the public regulates the government;

3. Political, the role of the party system to bind together through inter-dependence the officials of the two levels of government, as well as from state to state; and

4. Judicial, where the court serves as umpire of legislative constitutionality [grifos nossos]. ${ }^{26}$

Não é o objetivo deste trabalho abordar cada tipo de salvaguarda, por ora admitimos que essas definições são suficientes.

O que buscamos com a exposição dessas possíveis definições sobre os tipos de salvaguardas é demonstrar a diversidade de salvaguardas possíveis e como cada uma possui um gatilho diferente - mas ressalvando que elas podem entrar em ação concomitantemente, ou seja, que um mesmo fato acione diversas salvaguardas (e que às vezes é possível que o centro do conflito seja decidir qual salvaguarda irá atuar sobre o conflito, quais serão as regras do jogo).

Após o estabelecimento do arcabouço teórico, passemos à aplicação desses conceitos a casos práticos, o que faremos no tópico seguinte.

\subsection{PEC-33 e Royalties do pré-sal: análise de casos}

Nesse tópico, analisaremos dois casos de conflitos institucionais ocorridos no Brasil e ainda não solucionados, ou melhor dizendo, sobre os quais não foi tomada uma decisão com ânimo definitivo, restando ainda discussões em aberto. Convém salientar que se formos rigorosos nenhum conflito se encerra, ele apenas se transforma e passa a fazer parte da atmosfera semântica dos envolvidos (e afetados) e do meio como um todo. Quando esclarecemos que os conflitos que iremos analisar ainda estão em aberto significa que, dentro do design institucional (e jurídico) brasileiro atual, não existe uma decisão definitiva dada pelas instituições a quem compete tomar a decisão com esse ânimo - nos casos em questão, o poder Legislativo federal.

Apresentados esses esclarecimentos, é necessário dizer que não nos propomos a realizar um prognóstico ou qualquer tipo de previsão

\footnotetext{
${ }^{25}$ BEDNAR, Jenna. The robust federation - principles of design, p. 87 .

${ }^{26}$ BEDNAR, Jenna. The robust federation - principles of design, p. 96.
} 


\section{PESQUISAS SOCIOJURÍDICAS}

sobre esses conflitos, mas interpretá-los à luz do arcabouço teórico trazido. Também se deve pontuar que os casos escolhidos para análise são meramente exemplificativos, poderiam ser escolhidos outros, esses foram os escolhidos por tratarem de conflitos institucionais em órbitas diferentes (na PEC-33 é um conflito entre o Judiciário e o Legislativo; no caso dos royalties do pré-sal, é um conflito entre estados-membros da federação).

Tratemos primeiro do caso da PEC-33. Em 2011, o Deputado Federal Nazareno Fonteneles apresentou a proposta de emenda à constituição, com a seguinte ementa: Não é o objetivo deste trabalho abordar cada tipo de salvaguarda, por ora admitimos que essas definições são suficientes.

O que buscamos com a exposição dessas possíveis definições sobre os tipos de salvaguardas é demonstrar a diversidade de salvaguardas possíveis e como cada uma possui um gatilho diferente - mas ressalvando que elas podem entrar em ação concomitantemente, ou seja, que um mesmo fato acione diversas salvaguardas (e que às vezes é possível que o centro do conflito seja decidir qual salvaguarda irá atuar sobre o conflito, quais serão as regras do jogo).

Após o estabelecimento do arcabouço teórico, passemos à aplicação desses conceitos a casos práticos, o que faremos no tópico seguinte.

\subsection{PEC-33 e Royalties do pré-sal: análise de casos}

Nesse tópico, analisaremos dois casos de conflitos institucionais ocorridos no Brasil e ainda não solucionados, ou melhor dizendo, sobre os quais não foi tomada uma decisão com ânimo definitivo, restando ainda discussões em aberto. Convém salientar que se formos rigorosos nenhum conflito se encerra, ele apenas se transforma e passa a fazer parte da atmosfera semântica dos envolvidos (e afetados) e do meio como um todo. Quando esclarecemos que os conflitos que iremos analisar ainda estão em aberto significa que, dentro do design institucional (e jurídico) brasileiro atual, não existe uma decisão definitiva dada pelas instituições a quem compete tomar a decisão com esse ânimo - nos casos em questão, o poder Legislativo federal.

Apresentados esses esclarecimentos, é necessário dizer que não nos propomos a realizar um prognóstico ou qualquer tipo de previsão sobre esses conflitos, mas interpretá-los à luz do arcabouço teórico trazido. Também se deve pontuar que os casos escolhidos para análise são meramente exemplificativos, poderiam ser escolhidos outros, esses foram os escolhidos por tratarem de conflitos institucionais em órbitas diferentes (na PEC-33 é um conflito entre o Judiciário e o Legislativo; no caso dos royalties do pré-sal, é um conflito entre estados-membros da federação).

Tratemos primeiro do caso da PEC-33. Em 2011, o Deputado Federal Nazareno Fonteneles apresentou a proposta de emenda à constituição, com a seguinte ementa:

Altera a quantidade mínima de votos de membros de tribunais para declaração de inconstitucionalidade de leis; condiciona o efeito vinculante de súmulas aprovadas pelo Supremo Tribunal Federal à aprovação pelo Poder Legislativo e submete ao Congresso Nacional a decisão sobre a inconstitucionalidade de Emendas à Constituição [grifos nossos]. ${ }^{27}$

Inegável que semelhante emenda, caso aprovada, implicaria perda de poder por parte do Supremo Tribunal Federal (STF), e pode ser considerada uma contestação direta ao poder da corte, tanto que o Ministro Gilmar Mendes realizou diversas declarações polêmicas à imprensa, como "Eles [CCJ] rasgaram a Constituição. Se um dia essa emenda vier a ser aprovada é melhor que se feche o Supremo"28, o que levou à intervenção do Ministro Ricardo Lewandowski na discussão (à época presidente da corte), declarando que: "Quando os poderes agem dentro de sua esfera de competência, a meu

\footnotetext{
${ }^{27}$ BRASIL. Câmara dos Deputados. Projetos de lei e outras proposições. PEC 33/2011. Disponível em: <http://www.camara.gov.br/proposicoesWeb/fich adetramitacao?idProposicao $=503667>$. Acesso em: 20 ago. 2013.

${ }^{28}$ Cf. OLIVEIRA, Mariana. Se PEC 33 passar "melhor que se feche o Supremo" diz Gilmar Mendes. G1 Política. 25.04.2013. Disponível em: <<http:// g1.globo.com/politica/noticia/2013/04/se-pec-33-passar-melhor-que-se-feche-o-supremo-diz-gilmar-mendes.html>. Acesso em: 20 ago. 2013.
} 
ver, não há o que se falar em retaliação. E muito menos crise. Pelo contrário, os poderes estão ativos, funcionando e não há crise nenhuma." 29

Embora o Ministro Lewandowski tenha afastado a possibilidade de se tratar de um caso de retaliação, é essa uma suspeita, informal e não confirmada, que se tem - especialmente por se considerar que em 2011 começou a transitar no STF a Ação Penal 470, que condenou diversos participantes do esquema de corrupção conhecido como "mensalão", diversos deles associados ao governo, como José Dirceu e José Genoíno. Dessa forma, suspeita-se que existiria uma correlação entre AP-470 e a propositura da PEC-33.

$\mathrm{Na}$ análise que realizamos do caso, não é relevante decidir se a suspeita é verdadeira ou não, basta para nós que ela exista - estando assim presente na atmosfera semântica dos envolvidos, o simples fato de que os envolvidos no conflito (vamos polarizar o conflito entre o Legislativo e o Judiciário, mas temos ciência de que a situação, na prática, não é tão bem delimitada) acreditem que se trata de uma retaliação já altera suas estratégias negociais.

$\mathrm{Na}$ ótica do Judiciário, o que se vê é uma "transgressão" 30 que se propõe a retirar poder do STF; destacamos assim quatro elementos existentes em sua atmosfera semântica: (i) a vontade (agenda) de não ver seu poder reduzido; (ii) a vontade de aumentar seu poder institucional; (iii) a necessidade de se defender da beligerância de outra instituição; (iv) a intuição, mesmo que não confirmada, de que se trata de uma retaliação a um ato regularmente exercido pelo STF (é um universo de informações extremamente amplo, de forma que essa exposição não é exaustiva).

Nessa análise estamos sendo obrigados a realizar simplificações devido ao escopo reduzido desse trabalho. Necessário sempre destacar a influência, na atmosfera do sujeito institucional, da atmosfera dos sujeitos individuais - no caso concreto poderia se dizer que parte do ponto (iv) é composto da intersecção (interação) entre a atmosfera semântica da instituição e a do Ministro Gilmar Mendes (e de outros ministros, que também demonstraram sua desaprovação à medida, como Joaquim Barbosa). Observase que a análise completa do caso demandaria um estudo mais aprofundado a ser realizado posteriormente, se conveniente.

De que forma essa configuração da atmosfera do Judiciário impacta no jogo de poder? De diversas formas, mais precisamente no referente às estratégias negociais. $\mathrm{Na}$ situação descrita já estamos em uma hipótese de retaliação institucional (intergovernamental), pelo fato de que é um conflito entre os titulares de duas salvaguardas distintas (a política e a judicial), de forma que não é possível a utilização dessas duas salvaguardas para a resolução desse conflito, em particular.

A única forma de evitar essa retaliação é a utilização de outras salvaguardas, como a popular, ou a negociação direta - exatamente o que o Ministro Lewandowski está fazendo ao apaziguar a discussão, evitando a intensificação do conflito, mantendo-o em um patamar no qual é possível a negociação entre o Judiciário e o Legislativo. Obviamente a estratégia de cada ministro é diferente, mas, como um conjunto, é possível identificar duas tendências: a de se pronunciar publicamente contra a PEC-33, pressionando o Legislativo e procurando trazer a opinião pública a seu favor e a de amenizar a situação procurando negociar - após já ter demonstrado (pela imprensa) sua não concordância e sua capacidade de resistir a essa mudança.

Observe-se que se trata de uma estratégia muito diferente da empregada em um clima ameno no qual inexistissem tensões entre o Judiciário e o STF, como na maioria das vezes em que o STF declara a inconstitucionalidade de uma lei ou emenda. Em uma situação "normal", o STF aguardaria a promulgação da lei e o questionamento de sua constitucionalidade, para depois decidir se a declara ou não inconstitucional - não iria agir como o fez nesse caso, de maneira

\footnotetext{
${ }^{29}$ Cf. OLIVEIRA, Mariana. Não há crise entre Congresso e Supremo, diz Lewandowski. G1 Política. 25.04.2013. Disponível em: <http://g1.globo.com/ politica/noticia/2013/04/nao-ha-crise-entre-congresso-e-supremo-diz-lewandowski.html>. Acesso em: 20 ago. 2013.

${ }^{30}$ Lembrando, aqui, que a transgressão não é necessariamente alheia ao Direito, pode ser muito bem a utilização de ferramentas jurídicas para a obtenção de uma finalidade própria, pessoal ou institucional.
} 
preventiva, antecipando-se à promulgação da emenda (que pode nem vir a ser aprovada pelo Congresso Nacional e/ou sancionada pelo Presidente da República).

Nosso intuito com a análise desse caso é fornecer uma visão mais detalhada dos elementos que compõem o conflito (jogo de poder) e como a presença de diferentes aspectos na atmosfera semântica dos envolvidos pode impactar nas estratégias negociais das partes. Embora o foco tenha sido no Judiciário, o mesmo poderia ser feito para o Legislativo. Optamos pelo Judiciário por ser o STF uma instituição mais coesa (com menor número de sujeitos envolvidos no processo de tomada de decisão e negociação) de forma a facilitar a compreensão.

Tendo-se dito o suficiente sobre o caso da PEC-33, passemos à análise do outro caso à mão, referente à divisão dos royalties do petróleo extraído na camada do pré-sal.

Em 2007, o governo federal tornou pública a informação que fora encontrado petróleo em área marítima, na camada que se chamou de "pré-sal". Tratava-se da descoberta de grandes reservas petrolíferas, mas localizadas em profundidade muito superior (cerca de 7.000 metros) ao comumente explorado (que gira na casa dos 4.000 metros) e não existia tecnologia suficiente para realizar a exploração, o que demandaria investimentos no setor.

O fato é que as reversas encontradas se encontram em área que abrange a costa de três estados diferentes: São Paulo, Rio de Janeiro e Espírito Santo - e a discussão passou a orbitar exatamente ao redor deste fato, pois os estados recebem parcela dos lucros advindos do petróleo. Contudo, no caso concreto, a projeção do volume de petróleo a ser extraído é bastante alta, a ponto de motivar os estados não produtores a se organizarem para redistribuir o lucro, alterando a legislação que estabelece a divisão dos royalties do petróleo.

O conflito se tornou, dessa forma, uma disputa no Congresso Nacional entre os estados produtores e os não produtores, cada qual tentando angariar para si maior parcela possível dos lucros do petróleo. Diferentemente do caso da PEC-33, não estamos em quadro de conflito entre o Judiciário e o Legislativo, mas entre os estados-membros da federação, que utilizam todas as ferramentas possíveis para atingir a sua agenda.

Depois de longa discussão no Congresso Nacional foi aprovada e sancionada legislação que beneficiaria os estados não produtores, garantindo-lhes maior parcela dos lucros que o previsto inicialmente (embora em proporção inferior aos estados produtores). A reação foi imediata. No dia seguinte à sanção, os governadores dos três estados produtores (São Paulo, Rio de Janeiro eEspíritoSanto) ingressaram com medidas judiciais no STF $^{31}$ e uma dessas medidas, liminar proposta pelo estado do Rio de Janeiro para suspender a eficácia da lei, foi aprovada pela Ministra Carmen Lúcia ${ }^{32}$.

$\mathrm{O}$ mérito dessas medidas ainda não foi analisado pelo STF.

Nesse caso, a atmosfera semântica dos sujeitos em questão pode ser simplificada a uma questão meramente financeira (não que este ponto não seja complexo por si só, mas não existe a conjunção de diversos fatores) - de forma que os estados-membros procuram maximizar os lucros possíveis desse evento (extração de petróleo da camada do pré-sal). A posição adotada pelos estados produtores é a mais radical possível, a de tentar centralizar todos os lucros sem dividir com outros estados, o que torna o conflito um jogo de soma zero.

No entanto, o mais interessante desse conflito são as arenas de disputa, as salvaguardas utilizadas. Como se trata de um conflito entre estados da federação, que possuem igual posição hierárquica (em nível formal), não haveria, a princípio, nenhum mecanismo queimpulsionasse as partes à negociação: logo, a única saída possível

\footnotetext{
${ }^{31}$ Cf. CANÊDO, Felipe. Três estados recorrem ao STF contra partilha dos royalties do pré-sal. EM.Com. 16.03.2013. Disponível em: <http://www. em.com.br/app/noticia/politica/2013/03/16/interna_politica,357916/tres-estados-recorrem-ao-stf-contra-partilha-dos-royalties-do-pre-sal.shtml>. Acesso em: 20 ago. 2013.

${ }^{32}$ Cf. OTTA, Lu Aiko. Decisão do STF não altera leilões do pré-sal diz MME. Agência Estado. 19.03.2013. Disponível em:<http://economia.estadao.com. br/noticias/economia-geral,decisao-do-stf-nao-altera-leiloes-do-pre-sal-diz-mme,147676,0.htm>. Acesso em: 20 ago. 2013.
} 
seria a retaliação interinstitucional (neste caso, intergovernamental).

As salvaguardas institucionais aparecem exatamente para romper esse quadro e forcejar a negociação - no caso específico foram duas salvaguardas: a política e a judicial. A primeira arena desse conflito foi o Congresso Nacional ${ }^{33}$, em especial no Senado, onde se observou uma conjugação de forças entres os estadosprodutores com vistas a fortalecer sua posição nas negociações com outros estados, sobretudo em relação a estados com economia menos desenvolvida. Os estados produtores perderam nessa rodada de negociações e deflagraram outra ciações, em arena distinta, a da Presidência da República (saiu do âmbito do Legislativo e migrou para o do Executivo), tentando convencer a presidente a vetar a lei aprovada no Congresso.

O resultado final foi que a lei foi sancionada pela presidente sem vetos, restando derrotados os estados produtores dentro das arenas possíveis da salvaguarda política. Contudo, existe uma terceira arena possível, que é o poder Judiciário (já no âmbito de outro tipo de salvaguarda), na qual se obteve um relativo sucesso, com o deferimento de uma liminar que suspende os efeitos da lei, obviamente é um sucesso precário - afinal poderá ser revisto a qualquer momento e ser alterado na oportunidade de julgamento do mérito da ação.

\section{CONCLUSÃO}

O objetivo principal do presente trabalho é o de propor a utilização de um novo marco teórico para a análise das instituições (o que abrange também a federação), precisamente pelo fato de possuir um arcabouço teórico mais complexo que permita a compreensão e a análise de fenômenos que são tratados apenas como meras "patologias" pela ótica do estudo usual sobre federalismo e divisão de poderes e competências.

Cada caso apresentado serviu a um propósito específico de demonstrar, em aplicação empírica, parte dos conceitos desenvolvidos durante esse trabalho. No primeiro caso apresentado realizamos a investigação de elementos que compõem a atmosfera semântica de um dos envolvidos no conflito e como isso altera as estratégias negociais empregadas. No segundo caso tratamos com maior vagar sobre as salvaguardas institucionais e seu papel na delimitação do conflito, que é o de formar (organizar) as arenas nas quais se desenrolarão as rodadas de negociação - negociações estas que possuem estratégias negociais desenvolvidas pelos sujeitos, dentro das balizas delimitadas pelas salvaguardas institucionais, a partir de sua atmosfera semântica e da intersecção entre a atmosfera semântica das instituições e a dos indivíduos (ambos enquadráveis na classificação de sujeitos) sujeitas à poluição do meio.

A questão mais relevante é que os casos que trouxemos não se referem a problemas da realidade fática, a qual, aliás, não tem problemas - ela simplesmente é. O ponto de quebra é que a teoria não é capaz de compreender o fenômeno, buscando reduzi-lo em complexidade para fazê-lo "caber" na teoria. O que muitas vezes se classifica como "anômalo e patológico" são, na verdade, fatos comuns da vida cotidiana dos sujeitos (sejam as instituições, sejam os indivíduos que as compõem).

Deforma que nãoéadequadoestabelecer como "correto" um quadro fático que simplesmente não se observa - existe aqui uma grande falha da teoria. Pode-se dizer que estamos diante de um quadro no qual se tenta fazer o mesmo que os físicos no começo do século XX: aplicar a mecânica newtoniana (clássica) para explicar interações nos níveis atômico e subatômico, ou seja, tentar aplicar uma teoria inadequada ao fenômeno que se tenta observar.

Por fim, também devemos ressaltar o fato de que aceitamos a complexidade do mundo e que, apesar de algumas simplificações realizadas (como aceitação das ações como racionais voltadas a fins), o cerne da contribuição reside em associar a compreensão de dois elementos diferentes: o sujeito (com a compreensão de sua atmosfera semântica) e a negociação (como jogo

\footnotetext{
${ }^{33}$ Pelo fato de que uma das casas, o Senado, é composto por representantes dos estados-membros (três senadores por estado).
} 
de poder) - no qual estes dois elementos exercem interação mútua.

Afastamo-nos assim da dimensão "normativa", o centro da dimensão jurídica não deve ser a norma, e também da dimensão "valorativa", os valores também não são o centro da investigação, pois variam de indivíduo para indivíduo e é contraproducente estabelecer premissas valorativas aprioristicamente. Chegamos, por fim, a uma dimensão "descritiva", que procura compreender o fenômeno relacional (que abrange a interação institucional) como uma teoria da ação.

Em síntese, muito mais que obtermos uma resposta sobre como estudar o objeto, procuramos deixar de maneira clara a existência de complexidades na realidade fática que só são identificáveis dentro do arcabouço teórico utilizado; logo, qualquer abordagem que ignorar essas características será incompleta e fadada à incompletude.

O grande objetivo, o qual não tratamos aqui por ser de um escopo maior e incompatível com o meio utilizado, é entender como se dão os processos de interação e se é possível mensurar e prever dealguma forma comportamentos futuros, bem como reflexos na ordem jurídica positiva. É um objetivo deveras ambicioso e bastante difícil, mas pensamos que é melhor tentar expandir nossa compreensão dos fenômenos que nos cercam do que simplesmente tentarmos reduzir a complexidade desses fenômenos para que eles possam "caber" nas nossas teorias.

\section{REFERÊNCIAS}

ASHBY, William Ross. An introduction to cybernetics. Londres: Chapman \& Hall LTD, 1956.

BEDNAR, Jenna. The robust federation principles of design. Cambridge : Cambridge University Press, 2009.

The dialogic theory of judicial review: A new social science research agenda. George Washington Law Review. 78, v. 5, p. 1.178-1.190,
2010.

Subsidiarity and robustness: building the adaptive efficiency of federal systems. NOMOS: American Society for Political and Legal Philosophy. NYU Press, 2013.

BERTALANFFY, Ludwig Von. Teoria geral dos sistemas. Petrópolis: Vozes, 2006.

BRASIL. Câmara dos Deputados. Projetos de lei e outras proposições. PEC 33/2011. Disponível em: $<$ http://www.camara.gov.br/proposicoesWeb/fic hadetramitacao $?$ idProposicao $=503667>$. Acesso em: 20 ago. 2013.

CANÊDO, Felipe. Três estados recorrem ao STF contra partilha dos royalties do pré-sal. EM.Com. 16.03.2013. Disponível em: <http://www. em.com.br/app/noticia/politica/2013/03/16/ interna_politica,357916/tres-estados-recorremao-stf-contra-partilha-dos-royalties-do-pre-sal. shtml>. Acesso em: 20 ago. 2013.

OLIVEIRA, Mariana. Não há crise entre Congresso e Supremo, diz Lewandowski. G1 Política. 25.04.2013. Disponível em: <http:// g1.globo.com/politica/noticia/2013/04/naoha-crise-entre-congresso-e-supremo-dizlewandowski.html>. Acesso em: 20 ago. 2013.

Se PEC 33 passar "melhor que se feche o Supremo" diz Gilmar Mendes. G1 Política. 25.04.2013. Disponível em: <<http://g1.globo. com/politica/noticia/2013/04/se-pec-33-passarmelhor-que-se-feche-o-supremo-diz-gilmarmendes.html>. Acesso em: 20 ago. 2013.

OTTA, Lu Aiko. Decisão do STF não altera leilões do pré-sal diz MME. Agência Estado. 19.03.2013. Disponível em: <http://economia.estadao.com. $\mathrm{br} /$ noticias/economia-geral,decisao-do-stf-naoaltera-leiloes-do-pre-sal-diz-mme,147676,0. htm>. Acesso em: 20 ago. 2013.

PUGLIESI, Márcio. Teoria do direito. 2. ed. São Paulo : Saraiva, 2009. 
2 PESQUISAS SOCIOJURÍDICAS

. Filosofia geral e do direito. 2013.

RAWLS, John. Uma teoria da justiça. São Paulo:

Martins Fontes, 2000.

Recebido em: 22/04/2014

Aprovado em: 03/06/2014 